\title{
Principal Component Analysis in Industrial Colour Coating Formulations
}

\author{
José M. Medina-Ruiz \\ University of Minho, Center for Physics \\ Portugal
}

\section{Introduction}

Industrial coatings are functional multilayer thin-films of less than $150 \mu \mathrm{m}$ that provide a wide range of applications. They are useful to prevent corrosion, to enhance electrical isolation, weather resistance, ultraviolet and infrared protection, decorative purposes etc. Common examples are in everyday commercial products such as in plastics, woods, cosmetics, automotive coatings etc. and in the packaging and security industries (Lewis, 1988; Pfaff \& Reynders, 1999; Tracton, 2006). A fundamental issue concerns colour appearance and the consecution of striking visual effects. For this purpose, the introduction of new special-effect colorants has provided a wide range of colour effects that imitate those found for example in Morpho butterflies etc. (Kinoshita et al., 2008). Industrial colour coatings can mimic the surface colour appearance of metals (usually called metallic coatings), the mother pearl effect or pearlescent coatings as well as iridescence or the ability to change the colour as a function of the illumination and the viewing angle (Klein, 2010; Lewis, 1988; McCamy, 1996).

Optical characterization of these industrial coatings demands novel instrumentation and new approaches for precise color formulation in the laboratory and then, for non-destructive testing within the assembled line (Klein, 2010; Völz, 2001). Here I will focus on metallic and pearlescent coatings for automotive paint finishes, one of the largest colour markets in the world. In colour technology, principal-component analysis (PCA) is a standard procedure to uncover the spectral bands of the colorants when they are mixed together (Fairman \& Brill, 2004; Kohonen et al., 2006; Liszewski et al., 2010; Ohta, 1973; Tzeng \& Berns, 2005), to estimate the number of colorants (Tzeng \& Berns, 2005), to simplify the bi-directional reflectance distribution function (BRDF) into few detector positions (Takagi et al., 2005), to indentify the presence of special-effect pigments (Medina, 2008), to evaluate the scattering performance of pigments (Medina \& Díaz, 2011), and to develop computer-assisted colour rendering tools for colour styling (Seo et al., 2011). The purpose of this chapter is double. First, I will provide a basic introduction to automotive coatings and paint composition. The standard optical instrumentation will be also presented as well as a basic introduction to colorimetry or how the fundamental attributes of the human colour perception depend on the physical spectra (Wyszecki \& Stiles, 1982). And second, I will use PCA in a new and different perspective that consists to examine colour variability for in-line inspection and for pigment identification. There are a considerable number of errors that can modify the final 
appearance of metallic coatings during the different paint application processes. Accurate colour quality control in the laboratory and in the production line has a fundamental importance for colour recipe correction and fast diagnosis of colour batch production. Here I will show that trial-to-trial variability of reflectance spectra of metallic coatings during the paint application process can be mapped into a stochastic diffusion process. I will use PCA to uncover and to classify the underlying long-range structure of variability and to analyze how this affects to the different types of pigments. An estimation of the Hurst exponent will be given from the eigenvalue spectra (Gao et al., 2003). The Hurst exponent is a measure of the dispersion that has been widely used in the study of anomalous diffusion from the statistical point of view such as in hydrology, finance, etc. (Mandelbrot, 2001). The new approach based on PCA is especially important to better understand the global dependence of colour coating formulations from different car parts manufacturers (Streitberger \& Dössel, 2008).

\section{Automotive coatings}

Typical automotive coatings have four different layers (Streitberger \& Dössel, 2008). Fig. 1A represents a schematic representation of the cross-section of a car coating. The electrocoat and the primer surfacer fix the coating to the substrate and prevent against corrosion. After that, the base coat or binder constitutes the principal element and provides the fundamental characteristics related with colour, elasticity, brightness, dispersion and chemical resistance. Finally, the outermost layer is the clear coat or the transparent lacquer that protects the binder from the exterior. Different types of pigments are included in the binder. Their selection depends on the nature of the resin (polyesters, acrylics, etc.) and the paint application technology such as solvent-based, water-based (environmentally friendly) or powder coatings.

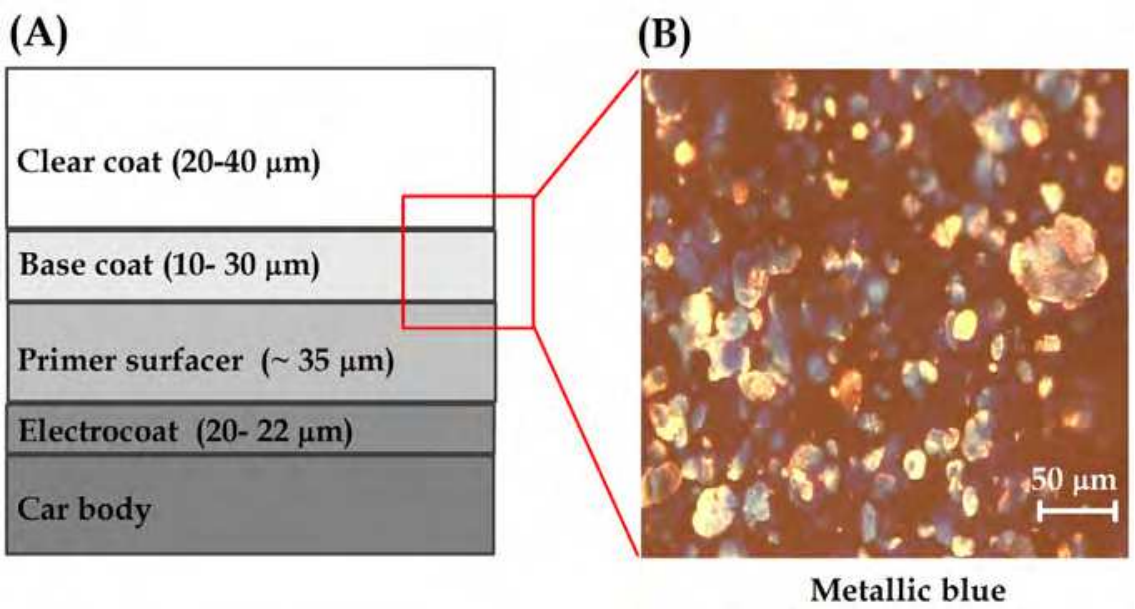

Fig. 1. (A) Schematic representation of the cross-section of a typical car coating and related layer thickness (in $\mu \mathrm{m}$ ). (B) Optical micrograph of a metallic blue coating containing aluminium flakes and conventional absorption blue pigments in the base coat. Bright field illumination (20x). 
The principal functions of pigments are to obtain a specific opacity or hiding power, to give remarkable colour effects, to provide stability against direct sunlight exposition and to provide resistance against different factors that affects corrosion. Some pigments are organic in nature and others are inorganic. Regarding special-effect pigments, they are metal-like (e.g. aluminium), pearl-like and interference flakes. They have, on average, a greater size (typically in $\mu \mathrm{m}$ ) in comparison with conventional absorption pigments (in $\mathrm{nm}$ ) and are often used to produce unusual colour variations in relation to the viewing angle (Klein, 2010; Lewis, 1988; Pfaff \& Reynders, 1999; Tracton, 2006). Fig. 1B shows an optical micrograph of a typical metallic blue coating containing lenticular aluminium flakes covered by organic blue (indanthrone) pigment nanoparticles in the base coat. Chemical pigments scatter the light in all directions or diffusive scattering. Further, they selectively absorb the incident radiation and can be formulated in accordance with the laws of subtractive colour mixing. Aluminium flakes, however, act like reflectors and scatter the light at the corners. In a different type of pigments, bright iridescent colours are often produced by thin-film interference pigments that obey the laws of additive colour mixing (Klein, 2010; Lewis, 1988; Pfaff \& Reynders, 1999; Tracton, 2006). Very popular interference pigments in automotive coatings are those containing mica flakes coated by different metal oxides such as titanium dioxide $\left(\mathrm{TiO}_{2}\right)$ (Klein, 2010; Lewis, 1988; Pfaff \& Reynders, 1999; Tracton, 2006). For a detail description of the deposition of pigments in the base coat in car coatings see (Streitberger \& Dössel, 2008).

Fig. 2A shows an optical micrograph of the metallic green coating containing yellowishgreenish interference pigments as indicated in example selected by the red square. In a perfect regular multilayer stack as the ideal case represented in Fig.2B, light at the interface of a tiny mica flake is partially reflected and partially transmitted producing a phase shift from a low-to-high refractive index media. Angle-dependent colour effects can arise from constructive interference (usually called goniochromism) (McCamy, 1996). In accordance with the Bragg condition, the reflected light is wavelength dependent and obeys the following equation (Hecht \& Zajac, 1974; Klein, 2010; Lewis, 1988):

$$
2 n d \cos (\alpha)=\left(m+\frac{1}{2}\right) \lambda
$$

where $m$ is an integer and $\lambda$ is the wavelength. The Bragg condition is also dependent on the refractive index of the material $n$, the thickness $d$, as well as the angle of refraction $\alpha$ between the illumination and the normal to plane of the sample. By selecting the appropriate thickness, tunable interference colours can de designed. The reflected rays are parallel to each other and the perception of colour (in our particular case yellowish) depends on the viewing angle (Klein, 2010; Lewis, 1988; Pfaff \& Reynders, 1999). The transmitted light through mica pigments corresponds to the complementary colour (i.e. bluish) and can interact with the substrate (black or white) (Klein, 2010; Lewis, 1988; Pfaff \& Reynders, 1999). In real mica-based pigments thickness is not a constant parameter and different colours can be observed inside the same flake as revealed in Fig. 2A. The control of the spatial dispersion of special-effect pigments is an important factor to obtain the desired colour effect. Both aluminium and interference flakes are, on average, oriented parallel to the substrate (Klein, 2010; Lewis, 1988; Streitberger \& Dössel, 2008). The flake orientation distribution can follow a Gaussian-type function with a long right tail (Kirchner \& 
Houweling, 2009; Sung et al., 2002). An important topic in car coatings is the concept of "colour harmony" or no perceptual colour differences between the different external parts of the car. Fig.3 shows an example of colour harmony.

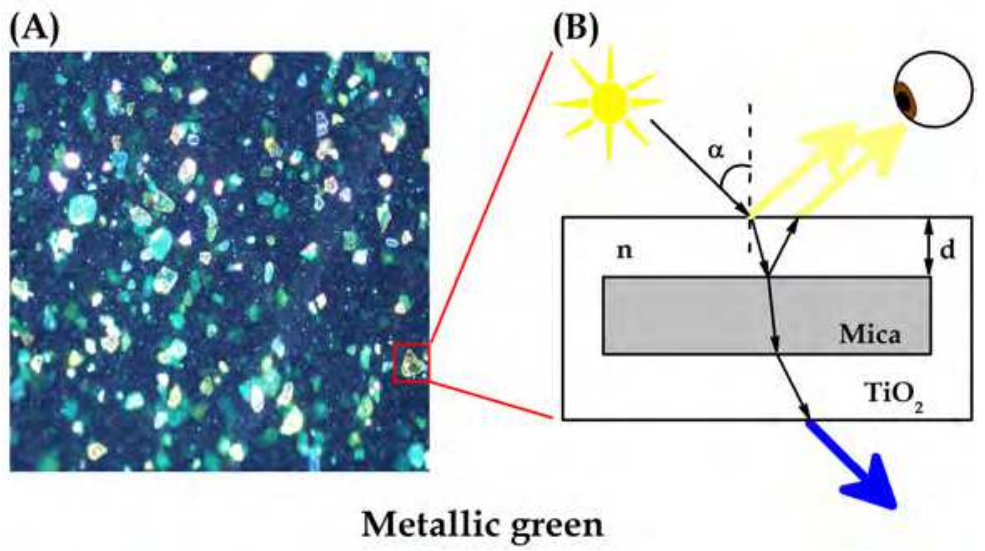

Fig. 2. (A) Optical micrograph of a metallic green coating containing greenish-yellowish interference pigments, aluminium flakes and opaque green absorption pigments. Darkfield illumination (20x). (B) Schematic representation of the cross-section of a mica flake coated by titanium dioxide $\left(\mathrm{TiO}_{2}\right)$ with thickness $d$ and refraction index $n$.

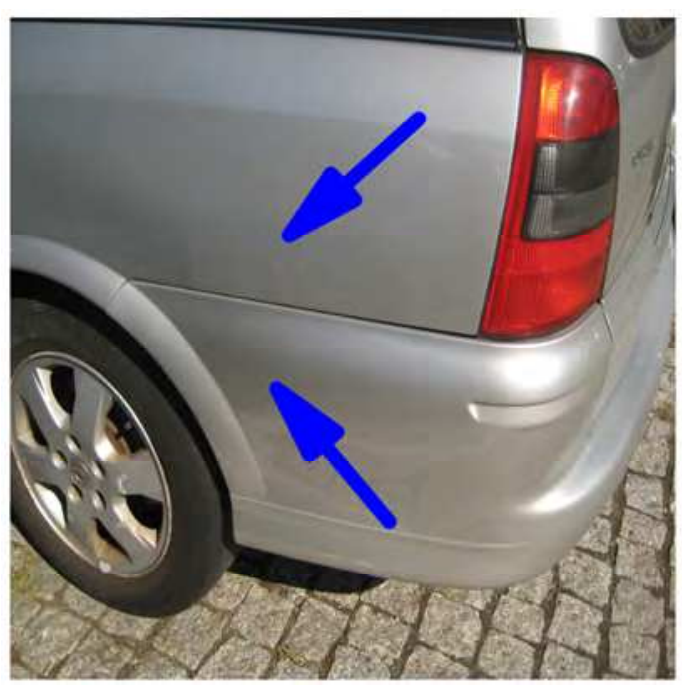

Fig. 3. Example of colour harmony in a silver-like coating containing aluminium flakes. Current colour designs must achieve no perceptible colour differences between the different external parts that integrate the car such as the car body and the fenders.

The analysis of colour harmony is a complex issue because bumpers, fenders, wings etc. are often provided by different manufacturers, each of them with similar paint procedures, and 
the car parts should be assembled all together in a specific automotive production line (Streitberger \& Dössel, 2008). I will show below that PCA can be applied to examine the intricate variability of the paint application processes during colour batch production and, thus, it can be used to study colour harmony.

\section{Spectroscopic instrumentation}

Spectrophotometer-based systems provide an estimation of the spectral reflectance distribution function, which describes the ratio of the reflected radiance to the incident irradiance from a surface for a specific illumination and detection positions (Klein, 2010; Völz, 2001; Wyszecki \& Stiles, 1982). Actually the CIE (Commission Internationale de l'Éclairage, International Commission on Illumination), promotes and regulates the standards conditions for reflectance and colour measurements. The measurement of the spectral reflectance and the colorimetric analysis of thin-films based on conventional chemical pigments and dyes have greatly simplified because matte and glossy surfaces have residual or no angular dependence. This is not the case of automotive coatings containing special-effect pigments and they require the estimation of the spectral reflectance function in the hemisphere centre at the sample or the BRDF.

The BRDF provides the spectral reflectance function of a surface measured in spherical coordinates using directional illumination. The complete characterization of the BRDF often assumes many positions or degrees of freedom (Baba \& Arai, 2003). This complicates the acquisition of reflectance spectra with a large number of readings at specific illumination and detection positions and their subsequent colorimetric evaluation in automotive coatings, a problem that has not been solved yet. Few standards of gonioappearance have appeared in the last years and portable multi-angle spectrophotometers are now using for testing and colour quality control. Fig. 4 shows a schematic representation of the detection geometries recommended for metallic coatings.

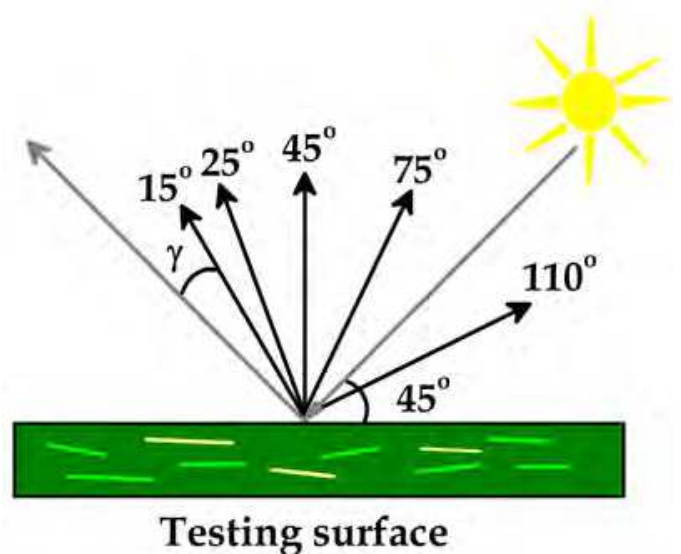

Fig. 4. Schematic representation of the cross-section of a metallic coating and the directional illumination at $45^{\circ}$ and the 5 angular detection configuration at the aspecular angle $\gamma$ of $15^{\circ}$, $25^{\circ}, 45^{\circ}, 75^{\circ}$ and $110^{\circ}$. 
For a fixed illumination angle (usually $45^{\circ}$ off from the normal of the measured surface), a set of predetermined detector angles is often defined from the specular reflection. DIN (The Deutsches Institut für Normung) recommends the use of three angles of $25^{\circ}, 45^{\circ}, 75^{\circ}$, and optionally $110^{\circ}$ from the specular (usually called the "aspecular angle" $\gamma$ ) (DIN 6175-2, 2001), whereas the ASTM (American Society for Testing Materials), prescribes three angles of $15^{\circ}, 45^{\circ}$, and $110^{\circ}$ (ASTM E2175-01, 2001). However, previous studies in pearlescent coatings have probed that these measurement geometries are not enough due to the angular dependence of the interference pigments on the illuminant position (see Eq. 1) (Cramer, 2002; Nadal \& Early, 2004). New industrial rules have been proposed (ASTM E2539-08, 2008) and novel scientific instrumentation is coming soon. Here I will restrict the PCA of reflectances using simultaneously those geometries compatible with the DIN (DIN 6175-2, 2001) and the ASTM (ASTM E2175-01, 2001).

\section{Colorimetry: Basic concepts and definitions}

The goal of colorimetry is to provide a simplified analysis of the illuminants and colouring surfaces using a three-dimensional colour space, which is a theoretical construction for classification and precise representation of colour properties (Wyszecki \& Stiles, 1982). Given a directional illumination source characterized by the energy distribution $S(\lambda)$, a testing surface with spectral reflectance $R(\lambda)$ and a observer (e.g. the human eye) located at a fixed detection position, colour properties of the surface can be labelled in the colour space using the colour coordinates. By the trichromatic principle (Wyszecki \& Stiles, 1982), the colour coordinates can be defined in the CIE standard colorimetric system by the tristimulus values X, Y and Z (Klein, 2010; Völz, 2001; Wyszecki \& Stiles, 1982):

$$
\begin{aligned}
& \mathrm{X}=\mathrm{k} \int \mathrm{S}(\lambda) R(\lambda) \overline{\mathrm{x}}_{10}(\lambda) \mathrm{d} \lambda \\
& \mathrm{Y}=\mathrm{k} \int \mathrm{S}(\lambda) R(\lambda) \overline{\mathrm{y}}_{10}(\lambda) \mathrm{d} \lambda \\
& \mathrm{Z}=\mathrm{k} \int \mathrm{S}(\lambda) R(\lambda) \overline{\mathrm{Z}}_{10}(\lambda) \mathrm{d} \lambda
\end{aligned}
$$

Where $\bar{x}_{10}(\lambda), \bar{y}_{10}(\lambda), \bar{z}_{10}(\lambda)$ are the CIE-1964 colour matching functions. The CIE-1964 colour matching functions define the spectral sensitivity of human eye for a standard observer that subtends a $10^{\circ}$ field of view. Spectral integration in Eq. 2 is often done between 400-700nm. The constant $k$ defines a normalization factor so that for a perfect white reflectance surface of $R(\lambda)=1$, the tristimulus value $Y$, which is related with the luminance content, equals to 100 for every illuminant (Klein, 2010; Völz, 2001; Wyszecki \& Stiles, 1982):

$$
k=\frac{100}{\int S(\lambda) \bar{y}_{10}(\lambda) d \lambda}
$$

Fig.5A represents the relative energy distribution of the illuminant D65, which imitates daylight conditions, and the standard incandescent illuminant A. Fig. 5B represents the spectral shape of the CIE-1964 colour matching functions. 
(A)

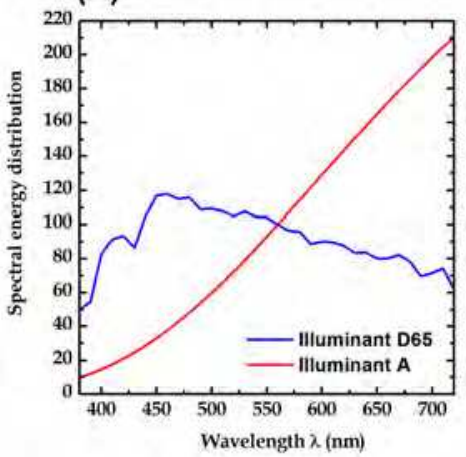

(B)

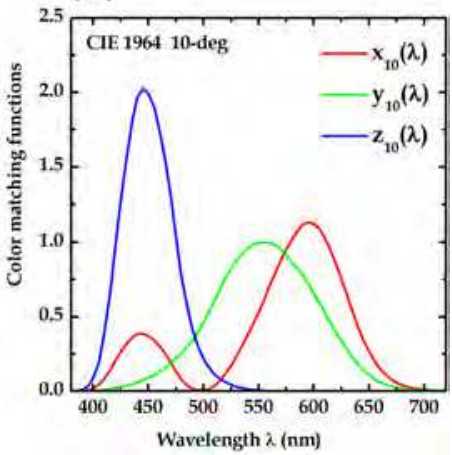

Fig. 5. (A) Relative energy distribution of the standard illuminants D65 and A recommended by the CIE. (B) CIE-1964 colour matching functions for the $10^{\circ}$ standard observer.

For pigmented thin-films as those in automotive coatings, it is more convenient to provide a transformation from the CIE-1964 colour space to the CIELAB perceptual colour space (Klein, 2010; Völz, 2001). In the CIELAB colour space, the new orthogonal colour coordinates are L* (the luminance axis), related with the brightness sensation (i.e. the white and black contribution) and the chromaticity coordinates $\mathrm{a}^{*}$ (red-green axis) and $\mathrm{b}^{*}$ (blue-yellow axis) that defines the chromatic plane. From the tristimulus values defined in Eqs. 2-3, the CIELAB coordinates can be calculated as follows (Klein, 2010; Völz, 2001; Wyszecki \& Stiles, 1982):

$$
\begin{aligned}
& \forall\left(\frac{X}{X_{n}}\right),\left(\frac{Y}{Y_{n}}\right),\left(\frac{Z}{Z_{n}}\right)>0.008856 \Rightarrow \\
& \Rightarrow\left\{\begin{array}{l}
X^{*}=\sqrt[3]{\frac{X}{X_{n}}} \\
Y^{*}=\sqrt[3]{\frac{Y}{Y_{n}}} \\
Z^{*}=\sqrt[3]{\frac{Z}{Z_{n}}}
\end{array}\right\}
\end{aligned}
$$

where $X_{n}, Y_{n}$ and $Z_{n}$ are the CIE tristimulus values of the reference illuminant used $\left(Y_{n}\right.$ equals to 100 for all the standard illuminants, see Eqs. 2-3):

$$
\begin{aligned}
& \forall\left(\frac{X}{X_{n}}\right),\left(\frac{Y}{Y_{n}}\right),\left(\frac{Z}{Z_{n}}\right) \leq 0.008856 \Rightarrow \\
& \Rightarrow\left\{\begin{array}{l}
X^{*}=7.787 \frac{X}{X_{n}}+0.138 \\
Y^{*}=7.787 \frac{Y}{Y_{n}}+0.138 \\
Z^{*}=7.787 \frac{Z}{Z_{n}}+0.138,
\end{array}\right\}
\end{aligned}
$$




$$
\begin{aligned}
& L^{*}=116 Y^{*}-16 \\
& a^{*}=500\left(X^{*}-Y^{*}\right) \\
& b^{*}=200\left(Y^{*}-Z^{*}\right)
\end{aligned}
$$

Positive values of $a^{*}$ and $b^{*}$ represents reddish and yellowish, respectively whereas negative values indicate greenish and bluish, respectively (Klein, 2010; Völz, 2001; Wyszecki \& Stiles, 1982). Colour coordinates $\mathrm{a}^{*}$ and $\mathrm{b}^{*}$ defined in Eq.6 are reminiscent of the chromaticopponent physiological organization of ganglion cells at the retina (Dacey, 2000). As an example, Fig.6A shows the reflectance spectra measured with a multi-angle spectrophotometer (400- $700 \mathrm{~nm}$ at $10 \mathrm{~nm}$ steps) for a typical green metallic coating containing aluminium, opaque green absorption nanopigments and mica-based interference pigments at the aspecular angles of $15^{\circ}, 25^{\circ}, 45^{\circ}, 75^{\circ}$ and $110^{\circ}$.

(A)

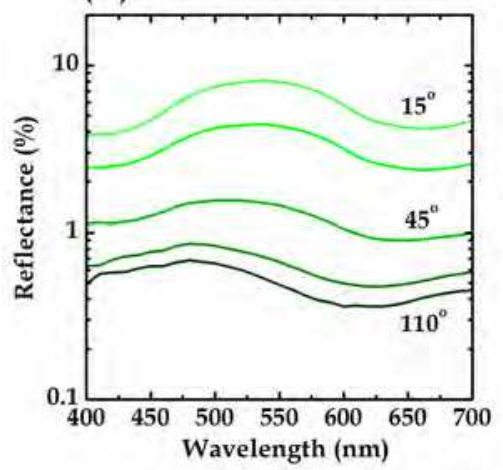

(B)

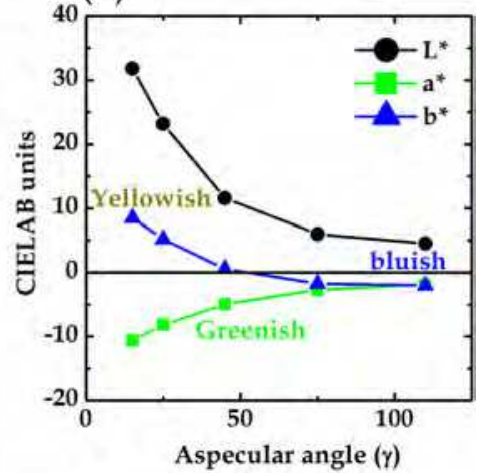

Fig. 6. (A) Reflectance spectra measured by a multi-angle spectrophotometer (X-Rite MA68II) at the aspecular angle $\gamma$ of $15^{\circ}, 25^{\circ}, 45^{\circ}, 75^{\circ}$ and $110^{\circ}$. (B) CIE L*, $\mathrm{a}^{*}$ and $\mathrm{b}^{*}$ colour coordinates calculated at different the aspecular angles. The reference illuminant was D65.

Because both aluminium and mica flakes are mainly oriented parallel to the substrate, bright interference colours are clearly manifested near the specular reflection at the aspecular angles $\gamma$ of $15^{\circ}$ and $25^{\circ}$, whereas reflection from diffusive multiple-light scattering and pigment absorption dominate far from the specular such as the aspecular angles $\gamma$ of $75^{\circ}$ and $110^{\circ}$ (Klein, 2010). In Fig. 6A maximum of reflectance shifts from greenish-yellowish (540 $\mathrm{nm})$ near the specular at $15^{\circ}$ to greenish-bluish $(480 \mathrm{~nm})$ far from the specular at $110^{\circ}$. Fig. $6 \mathrm{~B}$ shows the CIELAB colour coordinates $L^{*}, a^{*}$, and $b^{*}$ as a function of the aspecular angle $\gamma$ under the reference illuminant D65. Lightness values change from 31.8 CIELAB units at $\gamma=$ $15^{\circ}$ to 4.48 CIELAB units at $\gamma=110^{\circ}$. Direct visual observation with the naked eyes of the metallic green panel in a light booth and using a D65 daylight lamp validate the above colorimetric description.

\section{Principal component analysis of reflectances}

PCA is one common way to decorrelate reflectance spectra into few components that maximizes the variance accounted for (Fairman \& Brill, 2004; Ohta, 1973; Tzeng \& Berns, 2005). 
For this purpose, it is possible to treat the reflectance spectra of metallic coatings as vectors (as much dimensions as wavelengths) in the vector space of square-integrable functions $\mathbf{L}^{2}$. For example, given a reflectance dataset composed by $\mathrm{N}$ different reflectance elements between $400-700 \mathrm{~nm}$ at $10 \mathrm{~nm}$ steps (i.e. 31 dimensional vectors), it is possible to establish a linear decomposition of each spectral reflectance function $R_{j}(\lambda)$ around the mean reflectance of the database $\bar{R}(\lambda)$ (Fairman \& Brill, 2004; Ohta, 1973; Tzeng \& Berns, 2005):

$$
\begin{aligned}
& \forall \mathrm{j}=1,2, \ldots, \mathrm{N} \Rightarrow \\
& \Rightarrow \mathrm{R}_{\mathrm{j}}(\lambda)=\overline{\mathrm{R}}(\lambda)+\sum_{\mathrm{i}=1}^{31} \mathrm{~b}_{\mathrm{i}} \mathrm{Z}_{\mathrm{i}}(\lambda)
\end{aligned}
$$

where the coefficients $b_{i}$ are the coordinates in the new reference system or the principal components and $Z_{\mathrm{i}}(\lambda)$ are the new bases or eigenvectors in the $\mathbf{L}^{2}$ vector space. The first basis function $Z_{1}(\lambda)$ is uncorrelated with the second basis function $Z_{2}(\lambda)$ and its associated eigenvalue explains most of the variance and so on. Therefore, PCA of reflectance spectra of metallic coatings at each aspecular angle separately can uncover the spectral signature of the basis functions and permit to compare the bases across different aspecular angles for pigment identification (Medina, 2008).

\subsection{Anomalous diffusion assessed by principal component analysis}

Variability in the reflectance spectra and, thus, in the colour batch production of bumpers, fenders, wings, etc. can be mapped into a one-dimensional random walk model. The classical example of random walk is the irregular Brownian molecular motion of a pollen grain suspended in a liquid. Fig. 7A simulates a hypothetical Brownian diffusion process for

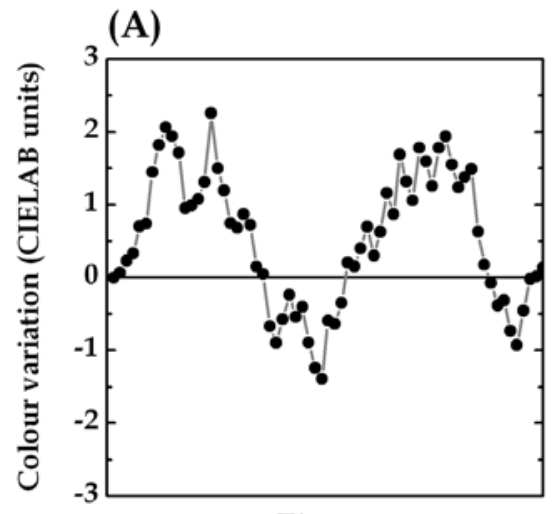

Time $t$
(B)

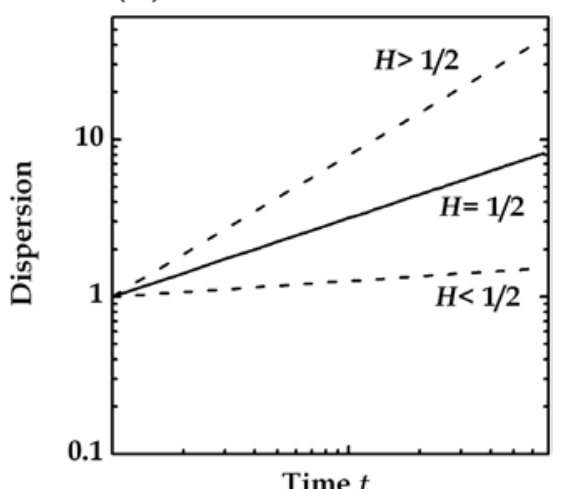

Fig. 7. (A) Illustration of a random walk model for the colour batch production of metallic coatings. Black dots in the time series correspond to the CIELAB colour coordinates measured in each painted panel relative to the master panel within the production line. (B) Double logarithmic plot of the dispersion as a function of time for different values of the Hurst exponent $H$. Solid and dashed lines correspond to the standard Brownian and fractional Brownian motion processes, respectively. 
colour production of metallic coatings. Here the position of the random walker at a single step refers to each painted piece in chronological order and is represented by the CIELAB colour coordinates relative to the reference master panel, i.e. $\Delta \mathrm{L}^{*}, \Delta \mathrm{a}^{*}, \Delta \mathrm{b}^{*}$ and can assume positive and negative values (Klein, 2010; Völz, 2001; Wyszecki \& Stiles, 1982).

In the proposed model, the mean square displacement of the colour differences can grow with time by a power law, $\mathrm{t}^{2 \mathrm{H}}$, where $H$ is the Hurst exponent and gives a measure of dispersion. A standard Brownian process has $H=0.5$ and defines the reference baseline (i.e. no correlation) to indentify the presence of anomalous diffusion. The generalization of the standard Brownian motion is called fractional Brownian motion with the Hurst exponent taking values between zero and unity (Mandelbrot \& Van Ness, 1968). When $H>0.5$ colour coordinates differences are positively correlated suggesting the presence of persistent deviations, i.e., an increase in the colour coordinates differences are more probably to be followed by another increase later in the scale of time. When $H<0.5$ colour coordinates differences are negatively correlated suggesting the presence of antipersistent deviations. That is, after an increase in the colour coordinates differences of the painted pieces relative to the master panel, it is more probably to obtain a decrease in the colour differences later in the scale of time. It has been proved that for a fractional Brownian motion process, the eigenvalue spectrum derived from PCA decays as a power law with exponent $\beta$. This exponent is related with the Hurst exponent (Gao et al., 2003):

$$
\beta=2 H+1
$$

The exponent $\beta$ in Eq. 8 can also take values lower than unity (i.e. $H=0$ ) and higher than three (i.e. $H=1$ ). In the former case, it may be related with fractional Gaussian processes defined as the derivative of the fractional Brownian motion (Mandelbrot, 2001; Mandelbrot \& Van Ness, 1968). A different definition of the exponent $\beta$ may be required and this issue remains to be determined. For $\beta>3$, they correspond to anomalous diffusion that grows faster than any traditional fractional Brownian motion process (Medina \& Díaz, 2011). Therefore, a double logarithmic plot of the eigenvalues as a function of the basis function order is a simple and valuable method to uncover the existence of power laws at different aspecular angles and, thus, to identify the presence of anomalous diffusion in metallic coatings using the model in Eq.8 as the reference framework (see Fig. 7B) (Gao et al., 2003; Medina \& Díaz, 2011).

\section{Example of principal component analysis in metallic coatings}

\subsection{Colorimetric description}

Figs. $8 \mathrm{~A}$ and $8 \mathrm{~B}$ represent the reflectance spectra and the $\mathrm{CIE} \mathrm{L}^{*} \mathrm{a}^{*} \mathrm{~b}^{*}$ colour coordinates of a typical blue metallic coating, respectively. Data correspond to the master panel at the aspecular angles of $15^{\circ}, 25^{\circ}, 45^{\circ}, 75^{\circ}$ and $110^{\circ}$ and were taken with a conventional multiangle spectrophotometer (X-Rite MA68 II). White and zero calibration were done in regular time sequences using a white ceramic tile and a black trap, respectively.

Near the specular reflection at $15^{\circ}$ and $25^{\circ}$, maximum of reflectance is found at $460 \mathrm{~nm}$ indicating a greenish-bluish colour whereas far from the specular the peak is reduced to almost the same reflectance value as in $540 \mathrm{~nm}$ and $640 \mathrm{~nm}$ and promotes the perception of bluish-reddish. Luminance values change from 30 CIELAB units at $15^{\circ}$ to 3.8 CIELAB units 
at $110^{\circ}$. Fig. 9 shows in the CIELAB colour space a three-dimensional representation of a test colour batch production (blue spheres).

\section{(A)}

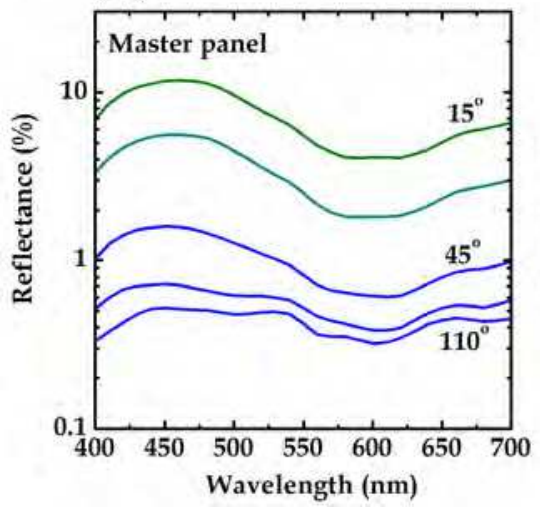

(B)

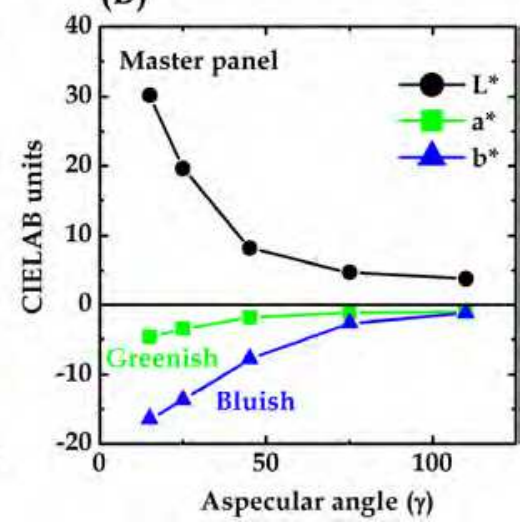

Fig. 8. (A) Reflectance spectra of a typical blue metallic coating at the aspecular angle $\gamma$ of $15^{\circ}, 25^{\circ}, 45^{\circ}, 75^{\circ}$ and $110^{\circ}$. (B) CIE $\mathrm{L}^{*}, \mathrm{a}^{*}$ and $\mathrm{b}^{*}$ colour coordinates calculated at different the aspecular angles. The reference illuminant was D65. Data indicate the master panel.

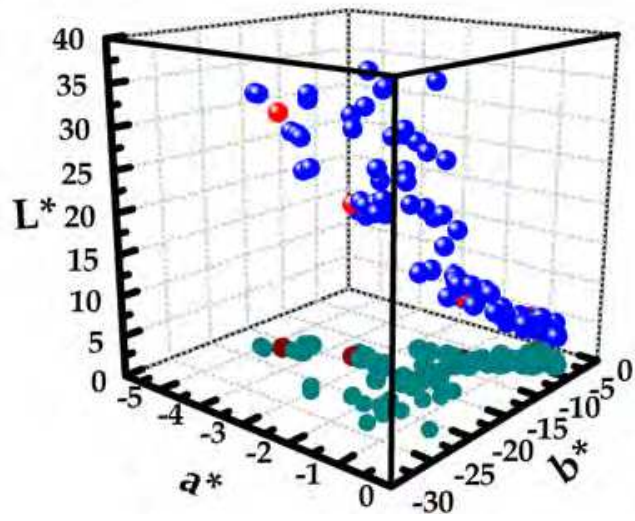

Fig. 9. Three-dimensional representation of the CIE $\mathrm{L}^{*}, \mathrm{a}^{*}$ and $\mathrm{b}^{*}$ colour coordinates corresponding to the blue metallic panels at the aspecular angle $\gamma$ of $15^{\circ}, 25^{\circ}, 45^{\circ}, 75^{\circ}$ and $110^{\circ}$. Blue spheres correspond to the different painted panels whereas red spheres indicate the colour coordinates of the master panel. Dark cyan and dark red solid circles represent the projection in the $a^{*} b^{*}$ plane, respectively. The reference illuminant was D65.

They consist of 21 successive painted panels and are representative of original equipment manufacturers in solventborne coatings (Streitberger \& Dössel, 2008). They were painted in the production line of a car supplier in Europe using a colour recipe to replicate the colour properties of the master panel in Fig. 8. They have aluminium flakes, opaque blue and carbon black absorption pigment nanoparticles and also mica-based interference flakes in a complex binder containing polyester, melamine and wax. The lacquer was transparent and 
was the same in all the 21 painted pieces. Reflectance spectra were measured at the end of the painted process at the 5 aspecular angles of $15^{\circ}, 25^{\circ}, 45^{\circ}, 75^{\circ}$ and $110^{\circ}$. Therefore, the reflectance database consists of a total of 105 reflectances between $400-700 \mathrm{~nm}$ at $10 \mathrm{~nm}$ steps. Then, they were converted to the CIELAB colour space using the D65 illuminant. The projection in the $a^{*} b^{*}$ plane is also displayed in Fig.9. Red spheres represent the colour coordinates of the master panel at different aspecular angles from Fig. 8B. The results indicate that the painted blue metallic panels occupy a characteristic colour volume and expand a specific colour map in the $a^{*} b^{*}$ plane around the reference master panel. In the colour batch production, the range (maximum - minimum) of luminance variations over the 5 aspecular angles was 35 CIELAB units whereas in the red-green axis a* and in the blueyellow axis $b^{*}$ the range was 4.6 and 22 CIELAB units, respectively.

\subsection{Basis functions}

PCA of reflectances was done over the 21 painted panels at each aspecular angle separately. Fig. 10 represents the first six basis functions near the specular reflection at $15^{\circ}$ (cyan solid lines) and far from the specular reflection at $110^{\circ}$ (blue solid lines). The first eigenvector or basis function has a peak around $410-430 \mathrm{~nm}$ and its shape remains almost invariant as a function of the aspecular angle. It accounts for more than $98 \%$ of the total variance at the aspecular angle of $15^{\circ}$ but only around $86 \%$ of total variance at $110^{\circ}$. It can be interpreted as the result of the aluminium flakes, which has a flat reflectance spectrum except at 400-420 $\mathrm{nm}$, covered by opaque absorption blue pigment nanoparticles in the binder (Baba \& Arai, 2003; Medina, 2008), in the same way as the spatial deposition illustrated in Fig 1B. That means that most of the variability associated with the blue metallic coatings corresponds to lightness and bluish changes as verified in Fig. 8B and Fig. 9.

The second and third basis functions are peaked a different wavelengths and represents more than $99 \%$ of the total variance accounted for. Their shape look similar and present a wavelength shift from $480 \mathrm{~nm}$ at $15^{\circ}$ to $410 \mathrm{~nm}$ at $110^{\circ}$ in the second basis function and from $420 \mathrm{~nm}$ at $15^{\circ}$ to $480 \mathrm{~nm}$ at $110^{\circ}$ in the third basis function. The effect of the aspecular angle on the basis functions can be interpreted as the presence of interference pigments within the base coat (Medina, 2008) (see also Eq. 1 and Fig. 2B). The next basis functions correspond to different corrections and are more difficult to interpret. This issue will be discussed further in the next section. In colour technology, a common procedure is to select only those basis functions that achieve $99 \%$ of the total variance accounted for or in some cases even more (Tzeng \& Berns, 2005). For example, in Fig. 10 it is required six basis function to represent more than $99.5 \%$ of the total variability of the reflectance spectra. I will show below that this statistical criterion is not adequate to examine the presence of diffusion process.

\subsection{Eigenvalue spectra}

Fig. 11 represents in a double logarithmic plot, the eigenvalue spectra of the blue metallic coatings from PCA at each aspecular angle. Only those eigenvalues at $15^{\circ}, 45^{\circ}$ and $110^{\circ}$ are displayed (the eigenvalue spectra for the aspecular angle of $25^{\circ}$ and $75^{\circ}$ are in intermediate positions). The results confirm that the eigenvalues decrease as the basis function order increases. Power laws were fitted using a least square procedure and the goodness-of-fit was assessed by the coefficient of regression R-square or $\mathrm{R}^{2}$ (Press et al., 1992). Far from the specular reflection at $110^{\circ}$ (blue triangles), from the third to the nineteenth eigenvalue a 
single power law regime is found representing $2.14 \%$ of the total variance account for. The coefficient of regression was $\mathrm{R}^{2}=0.99$ and the estimated exponent was $\beta=-3.9$. This suggests the presence of persistence correlations that grows faster than any fractional Brownian diffusion processes. They can be associated with the trial-to-trial variability in the spatial dispersion of absorption pigments within the base coat.

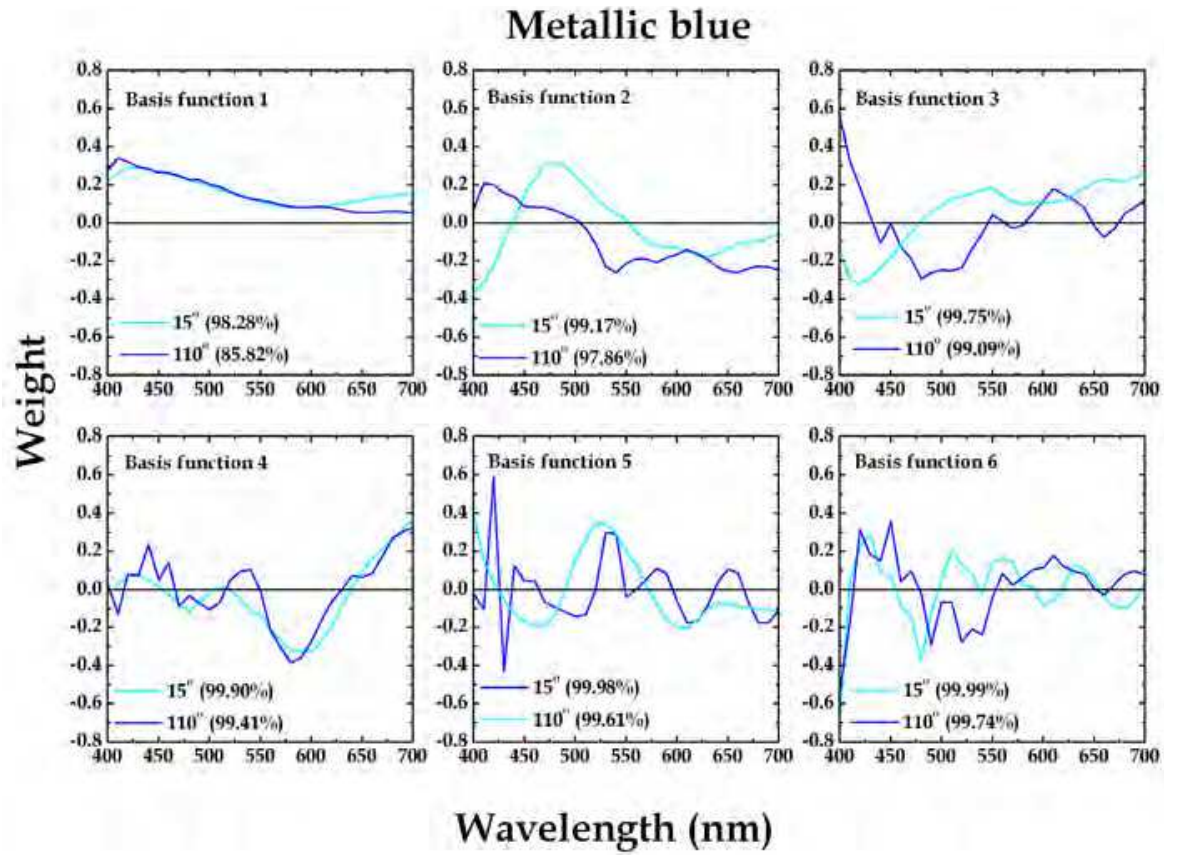

Fig. 10. PCA of reflectances from blue metallic coatings. Panel shows the first six basis functions. The percentage in parentheses indicates the cumulative variance account for from near-specular reflection at $15^{\circ}$ (cyan lines) to far from the specular at $110^{\circ}$ (blue lines).

At $110^{\circ}$ there is an upper cut-off that affects the first two eigenvalues and may reflect a finite-size effect from a small quantity of aluminium flakes and from the interference flakes that have a different orientation in comparison with the substrate. At all the aspecular angles, there is also a second limiting physical process in the eigenvalue spectrum that produces a lower cut-off. Interestingly, when we move from far to the specular reflection to an intermediate position such as at $45^{\circ}$ (grey squares), the first six basis function deviates from the above power law regime at $110^{\circ}$, this suggesting that more eigenvalues are affected by the presence aluminium and interference pigments oriented quasi-parallel to the substrate. Near the specular reflection at $15^{\circ}$, reflectance data contains most of the contribution from the aluminium and interference flakes oriented parallel to the substrate. From the second to the fifth eigenvalue a new power law regime is found $\left(R^{2}=0.86\right)$. The power law represents $1.70 \%$ of the total variance accounted and has an exponent $\beta=-1.9$. Since the first two basis functions in Fig. 10 are associated with the presence of mica-based flakes, the eigenvalue analysis suggest that trial-to-trial reflectance variability from interference pigments across different painted panels increase as a function of time 
following a Brownian diffusion process or equivalently, showing neither persistent nor antipersitent correlations (a Hurst exponent very close to $\mathrm{H}=0.5$ ). The second power-law regime at $15^{\circ}$ goes from the seventh to the nineteenth eigenvalue $\left(R^{2}=0.99\right)$. This power law has a slope $\beta=-3.8$, and, thus, very similar to the contribution expected at $110^{\circ}$ from absorption pigments but only represents less than $0.01 \%$ of the total variance accounted for.

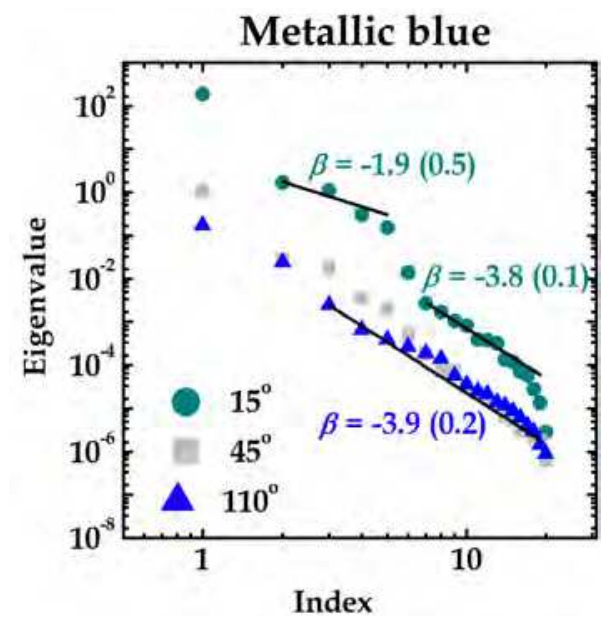

Fig. 11. Double logarithmic plot of the eigenvalue spectra from PCA of reflectances of the blue metallic coatings. Solid dark cyan circles, grey squares and blue triangles denote the eigenvalue spectrum at the aspecular angle $\gamma$ of $15^{\circ}$ (near-specular), $45^{\circ}$ (intermediate) and $110^{\circ}$ (far from the specular), respectively. Black solid lines indicate the adjusted power laws at different regimes. The slope $\beta$ denote the scaling exponent. Numbers in parentheses indicate their associate standard errors.

\section{Conclusions}

Principal component analysis of reflectance spectra is a powerful method to determine the possible sources of variability in surface colour appearance of industrial coatings. In comparison with the common statistical criterion used in colour technology that recommends to retain only few basis functions (Tzeng \& Berns, 2005), here a new analysis is introduced to examine the eigenvalue spectrum by power laws (Gao et al., 2003). Therefore, it was investigated the trial-to-trial variability in the colour batch production of metallic coatings in terms of fractional Brownian diffusion process and their correlations. This is important in colour recipe formulation and offers a novel approach to study colour harmony between different paint manufacturers. The PCA made in this chapter have dealt with the reflectance spectra collected at different aspecular angles and is representative of automotive coatings containing special-effect pigments (Streitberger \& Dössel, 2008). For the blue metallic coatings, it was concluded that the trial-to-trial variability of mica-based pigments across different painted panels is not correlated and follows a Brownian diffusion process with a Hurst exponent compatible with $H=0.5$. However, persistent trial-to-trial correlations with the same exponent at different aspecular angles were found, this suggesting a contribution from the deposition of absorption pigments in the base coat (see Fig. 11). This may be related with the 
use solventborne coatings and how the pigments are dispersed in the binder (Streitberger \& Dössel, 2008). Therefore, it would desirable to comparable these results with similar paint application processes as well as in waterborne and powder coatings. Finally, the methods presented in this chapter are not restricted to car coatings and can be applied in the study of different industrial colour process and coloured thin-films.

\section{Acknowledgments}

This work was supported by the European Regional Development Fund through Programa Operacional Factores de Competitividade-COMPETE (FCOMP-01-0124-FEDER-014588), by the National Portuguese Funds through the Fundação para a Ciência e Tecnologia -FCT (PTDC/CTM-MET/113352/2009), and by the Center for Physics, University of Minho, Portugal.

\section{References}

ASTM E2175-01 (2001). Standard Practice for Specifying the Geometry of Multiangle Spectrophotometers. (American Society for Testing and Materials).

ASTM E2539-08 (2008). Standard Practice for Multiangle Color Measurement of Interference Pigments. (American Society for Testing and Materials).

Baba, G. \& Arai, H. (2003). Gonio-spectrophotometry of metal-flake and pearl-mica pigmented paint surfaces. In Fourth Oxford Conference on Spectroscopy, A. Springsteen, and M. Pointer, eds. (Proceedings of the Society of Photo-Optical Instrumentation Engineers (SPIE)), pp. 79-86.

Cramer, W.R. (2002). Examples of interference and the color pigment mixtures green with red and red with green. Color Research and Application 27, pp. 276-281, ISSN 03612317.

Dacey, D.M. (2000). Parallel pathways for spectral coding in primate retina. Annual Review of Neuroscience 23, pp. 743-775, ISSN 0147-006X.

DIN 6175-2 (2001). Farbtoleranzen für Automobillackierungen - Teil 2: Effektlackierungen. (Deutsches Institut für Normung e.V.).

Fairman, H.S. \& Brill, M.H. (2004). The principal components of reflectances. Color Research and Application 29, pp. 104-110, ISSN 0361-2317.

Gao, J.B., Cao, Y.H. \& Lee, J.M. (2003). Principal component analysis of $1 / \mathrm{f}(\mathrm{alpha})$ noise. Physics Letters A 314, pp. 392-400, 0375-9601.

Hecht, E. \& Zajac, A. (1974). Optics Addison-Wesley Publishing Company, Inc, ISBN 9780805385663.

Kinoshita, S., Yoshioka, S. \& Miyazaki, J. (2008). Physics of structural colors. Reports on Progress in Physics 71, pp. 30, ISSN 0034-4885.

Kirchner, E. \& Houweling, J. (2009). Measuring flake orientation for metallic coatings. Progress in Organic Coatings 64, pp. 287-293, 0300-9440.

Klein, G.A. (2010). Industrial Color Physics Springer Science+Business Media LLC, ISBN 9781-4419-1196-4, New York.

Kohonen, O., Parkkinen, J. \& Jaaskelainen, T. (2006). Databases for spectral color science. Color Research and Application 31, pp. 381-390, ISSN 0361-2317.

Lewis, P.A. (1988). Pigment handbook, properties and economics, Vol 1, 2 edn John Willey \& Sons, ISBN 0-471-82833-5, New York. 
Liszewski, E.A., Lewis, S.W., Siegel, J.A. \& Goodpaster, J.V. (2010). Characterization of Automotive Paint Clear Coats by Ultraviolet Absorption Microspectrophotometry with Subsequent Chemometric Analysis. Applied Spectroscopy 64, pp. 1122-1125, ISSN 0003-7028.

Mandelbrot, B.B. (2001). Gaussian Self-affinity and Fractals Springer-Verlag, ISBN 0387989935, New York.

Mandelbrot, B.B. \& Van Ness, J.W. (1968). Fractional brownian motions, fractal noises and applications. Siam Review 10, pp. 422-437, ISSN 0036-1445.

McCamy, C.S. (1996). Observation and measurement of the appearance of metallic materials .1. Macro appearance. Color Research and Application 21, pp. 292-304, ISSN 03612317.

Medina, J.M. (2008). Linear basis for metallic and iridescent colors. Applied Optics 47, pp. 5644-5653, ISSN 0003-6935.

Medina, J.M. \& Díaz, J.A. (2011). Scattering characterization of nanopigments in metallic coatings using hyperspectral optical imaging. Applied Optics 50, pp. G47-G55, ISSN 0003-6935.

Nadal, M.E. \& Early, E.A. (2004). Color measurements for pearlescent coatings. Color Research and Application 29, pp. 38-42, ISSN 0361-2317.

Ohta, N. (1973). Estimating absorption-bands of component dyes by means of principal component analysis. Analytical Chemistry 45, pp. 553-557, ISSN 0003-2700.

Pfaff, G. \& Reynders, P. (1999). Angle-dependent optical effects deriving from submicron structures of films and pigments. Chemical Reviews 99, pp. 1963-1981, ISSN 00092665.

Press, W., Teukolsky, S., Vetterling, W. \& Flannery, B. (1992). Numerical recipes in C Cambridge University Press, 0-521-43108-5, New York.

Seo, M.K., Kim, K.Y., Kim, D.B. \& Lee, K.H. (2011). Efficient representation of bidirectional reflectance distribution functions for metallic paints considering manufacturing parameters. Optical Engineering 50, ISSN 0091-3286.

Streitberger, H.-J. \& Dössel, K.-F. (2008). Automotive Paints and Coatings, Second edn WileyVCH Verlag GmbH \& Co. KGaA, ISBN 978-3527309719.

Sung, L.P., Nadal, M.E., McKnight, M.E., Marx, E. \& Laurenti, B. (2002). Optical reflectance of metallic coatings: Effect of aluminum flake orientation. Journal of Coatings Technology 74, pp. 55-63, ISSN 0361-8773.

Takagi, A., Watanabe, A. \& Baba, G. (2005). Prediction of spectral reflectance factor distribution of automotive paint finishes. Color Research and Application 30, pp. $275-$ 282, ISSN 0361-2317.

Tracton, A.A. (2006). Coatings Technology Handbook, Third edn CRC press, Taylor \& Francis Group, LLC, ISBN 1-574-446495, Boca Raton, Florida.

Tzeng, D.Y. \& Berns, R.S. (2005). A review of principal component analysis and its applications to color technology. Color Research and Application 30, pp. 84-98, ISSN 0361-2317.

Völz, H.G. (2001). Industrial color testing, fundamentals and techniques, 2 edn Wiley VCH Verlag GmbH \& Co. KGaA, ISBN 3-527-30436-3.

Wyszecki, G. \& Stiles, W.S. (1982). Color science: concepts and methods, quantitative data and formulae, 2 edn John Wiley \& Sons, ISBN 0-471-021067, New York. 


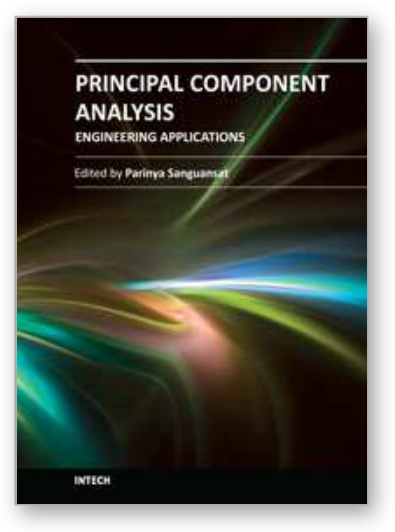

\author{
Principal Component Analysis - Engineering Applications \\ Edited by Dr. Parinya Sanguansat
}

ISBN 978-953-51-0182-6

Hard cover, 230 pages

Publisher InTech

Published online 07, March, 2012

Published in print edition March, 2012

This book is aimed at raising awareness of researchers, scientists and engineers on the benefits of Principal Component Analysis (PCA) in data analysis. In this book, the reader will find the applications of PCA in fields such as energy, multi-sensor data fusion, materials science, gas chromatographic analysis, ecology, video and image processing, agriculture, color coating, climate and automatic target recognition.

\title{
How to reference
}

In order to correctly reference this scholarly work, feel free to copy and paste the following:

José M. Medina-Ruiz (2012). Principal Component Analysis in Industrial Colour Coating Formulations, Principal Component Analysis - Engineering Applications, Dr. Parinya Sanguansat (Ed.), ISBN: 978-953-510182-6, InTech, Available from: http://www.intechopen.com/books/principal-component-analysis-engineeringapplications/principal-component-analysis-in-industrial-color-coating-formulations

\section{INTECH}

open science | open minds

\author{
InTech Europe \\ University Campus STeP Ri \\ Slavka Krautzeka 83/A \\ 51000 Rijeka, Croatia \\ Phone: +385 (51) 770447 \\ Fax: +385 (51) 686166 \\ www.intechopen.com
}

\author{
InTech China \\ Unit 405, Office Block, Hotel Equatorial Shanghai \\ No.65, Yan An Road (West), Shanghai, 200040, China \\ 中国上海市延安西路65号上海国际贵都大饭店办公楼405单元 \\ Phone: +86-21-62489820 \\ Fax: +86-21-62489821
}


(C) 2012 The Author(s). Licensee IntechOpen. This is an open access article distributed under the terms of the Creative Commons Attribution 3.0 License, which permits unrestricted use, distribution, and reproduction in any medium, provided the original work is properly cited. 